\title{
Democracia y liberalismo: una relación pragmática*
}

Fecha de entrega: 2 de junio de 2017

Fecha de evaluación: 26 de julio de 2017

Fecha de aprobación: 11 de agosto de 2017

\author{
Mario García Berger**
}

\section{Resumen}

El propósito central de este ensayo es proponer que entre la democracia y el liberalismo existe una relación pragmática. Para ello primero rechazaré la tesis de que este nexo es de tipo lógico-conceptual, así como la idea de que se trata meramente de un nexo contingente, para lo cual retomaré las concepciones de John Stuart Mill y Hans Kelsen. En suma, lo que sostendré es que los modelos democráticos, en tanto métodos de creación normativa, no implican ni las libertades políticas ni las económicas, aunque sí hay lo que llamaré una relación pragmática entre la democracia y el liberalismo, por lo que ser demócrata y antiliberal, o liberal y no demócrata, es una contradicción performativa.

Palabras clave: democracia, liberalismo, relación pragmática, contradicción performativa, John Stuart Mill, Hans Kelsen.

* El presente artículo es un producto derivado de la investigación del autor sobre la relación entre ética y derecho en la obra de Hans Kelsen. DOI: http://dx.doi.org/10.15332/s0120-8462.2017.0117.01

** Doctor en Filosofía por la Universidad Nacional Autónoma de México. Profesor investigador en la Universidad Autónoma de la Ciudad de México.mgberger@live.com 


\title{
Democracy and liberalism: a pragmatic relationship
}

\author{
Mario García Berger
}

\section{Abstract}

The central purpose of this essay is to propose that between democracy and liberalism there is a pragmatic relationship. For this, I will first reject the thesis that this relationship is logical-conceptual, as well as the idea that it is merely a contingent relationship, for which I will return to the concepts of John Stuart Mill and Hans Kelsen. In short, what I will argue is that democratic models, as methods of normative creation, do not imply either political or economic freedoms, although there is what I will call a pragmatic relationship between democracy and liberalism, so being a democrat and anti-liberal, or liberal and non-democratic, is a performative contradiction.

Keywords: democracy, liberalism, pragmatic relationship, performative contradiction, John Stuart Mill, Hans Kelsen.

\section{Democracia e liberalismo: uma relação pragmática}

\section{Mario García Berger}

\section{Resumo}

O propósito central deste ensaio é propor que entre a democracia e o liberalismo existe uma relação pragmática. Para isso, primeiro rejeitarei a tese que este nexo é do tipo lógico-conceptual, assim como a ideia de que se trata meramente de um nexo contingente, para o qual retomarei as concepções do John Stuart Mill e Hans Kelsen. Em suma, 
o que sustentarei é que os modelos democráticos, tanto métodos de criação normativa, não implicam nem as liberdades políticas nem as econômicas, embora há sim o que denominarei uma relação pragmática entre a democracia e o liberalismo, pelo que ser democrata e antiliberal ou liberal e não democrata, é uma contradição performativa.

Palavras-chave: democracia, liberalismo, relação pragmática, contradição performativa, John Stuart Mill, Hans Kelsen.

\section{Introducción}

En el debate académico la relación entre democracia y liberalismo ha sido objeto de distintas interpretaciones. En este trabajo me interesa resaltar especialmente dos de ellas: la que sostiene que la democracia moderna y la ideología liberal están vinculadas de forma conceptual, es decir, que entre ellas hay una relación necesaria, que no puede entenderse la una sin la otra. La segunda lectura es que si bien los sistemas democráticos coinciden históricamente con el surgimiento del liberalismo político-económico, y ambos se apoyan, no tienen entre sí un nexo conceptual sino contingente, por lo que son posibles las democracias no liberales.

Mi propósito es analizar estas dos interpretaciones, para lo cual retomaré ideas de John Stuart Mill y Hans Kelsen, para después ofrecer mi propia visión, que si bien es más afín a la segunda lectura mencionada, tiene algunas diferencias con ella. En suma, sostendré que los modelos democráticos, en tanto métodos de creación normativa, no implican ni las libertades políticas ni las económicas, aunque sí hay lo que llamaré una relación pragmática entre la democracia y el liberalismo, por lo que ser demócrata y antiliberal, o liberal y no demócrata, es una contradicción performativa.

\section{La relación conceptual entre democracia y liberalismo}

Para quienes sostienen esta posición, la doctrina democrática es el corolario natural del pensamiento liberal (Bobbio, 1989b), pues aquella implica el respeto y el fomento de las libertades civiles (de expresión, pensamiento, prensa, religión, etcétera). Su cabal ejercicio solo es posible en un régimen representativo, en donde estas libertades se consagran como derechos individuales y se propician las condiciones materiales para su plena vigencia. Asimismo, el disfrute de dichas libertades desarrolla las virtudes 
morales y las capacidades intelectuales y prácticas que son condición indispensable para que los sistemas democráticos se consoliden y fructifiquen. Sin ellas, a decir de Stuart Mill, el abstencionismo electoral amenaza con hacer de las instituciones populares meros instrumentos de la tiranía. Esto se da, por ejemplo, cuando una sola clase monopoliza en su beneficio la representación nacional. El estado de opresión que así surge es el más difícil de erradicar, en virtud de la envoltura de legitimidad que lo cubre.

Por otra parte, el sostenimiento de la democracia exige una opinión pública alerta y vigorosa, que sirva de apoyo al poder legislativo en su incesante lucha por detener los constantes embates del ejecutivo para extender su ámbito de influencia. En tal virtud, sostiene Mill, el éxito de los gobiernos depende del grado en que desarrollen en los ciudadanos aquellas capacidades intelectuales y prácticas, así como de su aprovechamiento para la buena conducción de los asuntos públicos.

El filósofo inglés añade, a los requisitos para el adecuado funcionamiento de la democracia, la seguridad de la propiedad, pues la certidumbre que da el saber de que el uso y disfrute de nuestras posesiones está a salvo de intromisiones ajenas, propicia mayores niveles de productividad y de progreso material en las sociedades. Si los hombres no pudiesen gozar con tranquilidad de los bienes que han obtenido legítimamente, no habría un elemento esencial de la cohesión social que es la confianza. Una sociedad desconfiada no prospera, dado que sus niveles de ahorro y de inversión son bajos por la misma falta de seguridad, lo que además, se puede añadir, la pone en riesgo de que se disuelvan los vínculos normativos éticos y jurídicos que hacen posible la convivencia social (Mill, 1982).

\section{El concepto de democracia}

Kelsen abre su obra, Esencia y valor de la democracia, explicando que el método que seguirá en ella consiste en exponer la democracia en su forma ideal, para después describir cómo se concreta en la realidad. Se establece así una distinción entre el ideal y sus aplicaciones. El modelo ideal de democracia, de acuerdo con el cual los sujetos a las normas jurídicas son a la vez sus creadores, es irrealizable en los hechos, pues el enorme crecimiento demográfico de los estados modernos hace imposible la participación directa en los procesos legislativos de todos aquellos con derechos políticos. Además, como ha señalado por ejemplo Bobbio (2012), no todas las personas están 
dispuestas a dedicar parte de su tiempo a la toma de decisiones políticas, como lo demanda una democracia directa. En consecuencia, son razones técnico-sociales las que limitan la participación política a la creación y control del mecanismo formador del orden social.

Por su parte, en el paradigma de la autocracia la "voluntad estatal" es producto de una sola persona. Kelsen señala que este modelo tampoco ha existido en su forma pura en la realidad, pues a lo largo de la historia los autócratas han delegado ciertas funciones en otras personas. Así, ambos paradigmas son parámetros mediante los cuales podemos describir las características de los gobiernos existentes. Un régimen será más o menos democrático o autocrático en la medida que se acerque o se aleje del respectivo ideal (Kelsen, 1974).

La concepción kelseniana de las formas ideales explica el hecho de que los regímenes políticos suelen tener elementos de ambos modelos. Así, por ejemplo, podemos encontrar lugares en donde exista una muy amplia libertad de opinión pero el sistema para la conformación del poder legislativo tenga rasgos antidemocráticos. Stuart Mill sostiene que el sistema representativo no ha logrado ampliar los beneficios de la libertad política a todas las clases sociales, por lo que aún está lejos del paradigma de la participación de todos en la creación del orden estatal. La democracia, afirma, es el gobierno de todo el pueblo por todo el pueblo igualmente representado. Sin embargo, tal como se practica, es el gobierno de todo el pueblo por una simple mayoría exclusivamente representada. En el primer caso, la participación política es igualitaria, mientras que en el segundo una mayoría privilegiada rige los destinos de los demás (Mill, 1982). No obstante, la coincidencia entre Kelsen y Mill cuando dicen que la democracia real es imperfecta, para el primero el ideal democrático tiene una función meramente explicativa, en tanto que para el segundo se trata de un estado de cosas que es realizable en los hechos (Mill, 1982).

\section{El parlamentarismo}

Lo anterior conduce a la cuestión del parlamentarismo, objeto de reñidas luchas a fines del siglo xVIII y principios del XIX. Sobre este tema también ambos autores comparten algunos puntos de vista. Desde la perspectiva milliana, el parlamento es: 
... la arena donde, no sólo la opinión general del país, sino la de los diversos partidos en que se divide, $y$, en lo posible, la de todos los individuos eminentes que encierra, puede producirse y provocar la discusión. Cada ciudadano está seguro de encontrar allí alguno que exponga su opinión [...], y no solamente a amigos y partidarios, sino también a adversarios políticos, con lo que sufrirá la prueba de la controversia. (Mill, 1982, p. 65)

Como se puede apreciar, para Mill la discusión de todas las doctrinas y opiniones en el seno de la representación nacional fomenta el espíritu público. Desde su mirada, el antagonismo de puntos de vista estimula la creatividad y evita que la costumbre convierta en dogmas las ideas más vivas. El constante debate de nuestras concepciones, aún de las que han probado ser verdaderas, nos obliga a proporcionar nuevos argumentos en su defensa. Con esto se revitalizan y no se convierten en letra muerta. Así mismo, el filósofo inglés destaca la conciliación como un elemento sustancial de la actividad legislativa en los gobiernos libres. El mejor sistema parlamentario, sostiene, es aquel donde las decisiones son resultado de la concertación entre los partidos políticos (Mill, 1982).

Por su parte, Kelsen afirma que el parlamentarismo es la única forma en que puede plasmarse la democracia dentro de la realidad social presente, es decir, es la única técnica a nuestro alcance para estructurar un orden estatal. Este procedimiento requiere concertación entre las distintas fuerzas representadas, tolerancia hacia las opiniones divergentes y la consolidación de un sistema competitivo de partidos. La voluntad colectiva debe ser fruto de la transacción entre los diversos intereses. La influencia de cada grupo en la dirección de los acuerdos dependerá de su fuerza electoral. La negociación, sostiene Kelsen, consiste en posponer lo que estorba a la unión a favor de lo que contribuye a ella, lo que no significa renunciar a las legítimas diferencias. La transacción no es sinónimo de claudicación; por el contrario, presupone una cultura de la tolerancia, que propicia el examen de todas las opiniones con el ánimo de encontrar y reconocer las razones en el argumento de los otros. Implica también reconocer que la verdad no está de un solo lado, sino que es resultado del empeño común. En suma, exige eliminar los casos de aplastamiento de las minorías por parte de la mayoría.

Para lograr esto es necesario la articulación del pueblo en partidos políticos. Solo así se crean las condiciones orgánicas para la actividad legislativa. Los partidos se 
definen como instrumentos para la formación de la voluntad colectiva, que reúnen a los afines en ideas con objeto de garantizarles una influencia eficaz en la marcha de la vida pública. En el parlamento se expresa de manera inequívoca el estado de civilización de una nación (Kelsen, 1974).

Para nuestros autores, la democracia representativa, a pesar de sus virtudes, tiene debilidades que la han colocado bajo la mira de sus críticos. La más grave es que limita la acción política de los ciudadanos a la emisión del voto. Esto, a su vez, plantea el problema de la relación entre los representantes y sus electores. Al respecto, Mill manifiesta un punto de vista que podríamos llamar intermedio. Por un lado, acepta que si el mandato otorgado por el pueblo a los legisladores fuera imperativo, de manera que tuviesen que adecuar sus decisiones a la voluntad de este, se diluiría el beneficio que puede obtenerse de la mayor preparación y experiencia de los representantes en el manejo de los asuntos públicos. Pero, por otro lado, es necesario que los sentimientos y creencias de los ciudadanos no sean ignorados completamente. La solución que propone el filósofo inglés a este dilema es conceder libertad a los legisladores para que actúen conforme a su propio juicio en la mayor parte de las deliberaciones, cuidando tan solo que su opinión no contradiga las creencias básicas del pueblo en torno a la organización social. Además, él veía en las asambleas y gobiernos locales ámbitos propicios para una participación directa de los individuos en la creación de leyes y en la conducción de la administración gubernamental (Mill, 1982).

Por su parte, Kelsen apunta que la ampliación de instrumentos como el referéndum y la iniciativa popular incrementaría la actividad política de los ciudadanos. Con respecto al primero dice que si la decisión plebiscitaria fuese contraria a los sentimientos del parlamento, procedería su disolución y la elección de uno nuevo. Esto es congruente con el principio de representación popular, porque los desacuerdos mostrarían que el órgano no interpreta adecuadamente las creencias básicas de la mayoría. Medidas adicionales para mejorar la imagen y el funcionamiento de la asamblea nacional sería suprimir la inmunidad judicial de los legisladores, principal causa de la conducta irresponsable en que algunos incurren, y la formación de comisiones especializadas en los diversos campos de gobierno, constituidas a base de profesionales electos democráticamente. La dificultad que en este punto advierte Kelsen es la de distinguir los asuntos que corresponderían a la cámara general y aquellos que serían responsabilidad de las comisiones especiales, dado que casi todo asunto público contiene factores económicos y políticos, por lo que habría 
necesidad de resolver los temas relevantes mediante acuerdo de ambas cámaras (Kelsen, 1974).

Un aspecto de suma importancia en los regímenes democráticos es el mecanismo para integrar el poder legislativo. Nuestros autores coinciden en señalar que el mejor método para ello es la representación proporcional. Este tipo de elección asegura la presencia en el parlamento del mayor número de minorías, aunque como afirma Kelsen, siempre habrá grupos tan pequeños que no alcancen ningún escaño. La proporcionalidad en la representación, comenta Stuart Mill, garantiza que los intereses de una buena parte de los ciudadanos sean al menos escuchados y defendidos por personas identificadas con ellos, lo que asegura su eficaz promoción. Así mismo, dicho sistema previene contra el más terrible y persistente de los males que amenaza a las democracias: la tiranía de la mayoría (Mill, 1982).

Se ha criticado al método de representación proporcional su tendencia a la atomización de las fuerzas políticas, lo que entorpece el desarrollo de los procesos legislativos. Kelsen (1974) comenta que la solución a esta dificultad es la coalición de partidos. Habría que añadir que en algunos países existe una cláusula de gobernabilidad, que de requerirse otorga a la organización más votada el número necesario de representantes para alcanzar el control parlamentario.

\section{Democracia y liberalismo}

Analicemos ahora la relación entre democracia y liberalismo. Para ello tomaremos como punto de partida la distinción kelseniana entre libertad natural y libertad política. La primera es distintiva de la anarquía y se concibe en términos de no sujeción a poder alguno. En cambio, es políticamente libre quien a pesar de estar sometido, lo está solamente a su propia voluntad. Esta es la libertad democrática, única compatible con la institución de autoridades. De lo anterior se desprende que las minorías sin representación en el parlamento están privadas de ella.

Los derechos políticos ya no se entienden como protección del individuo frente al Estado, sino de los grupos minoritarios frente a la mayoría absoluta. Con la transformación del concepto natural de libertad en su acepción jurídico-política, se transita, nos dice Kelsen (1974), del liberalismo a la democracia. El régimen representativo es el que mejor resuelve la contradicción entre libertad natural y orden social, porque 
los ciudadanos solo se someten a las leyes que ellos mismos han creado indirectamente. El lugar de aquella es ocupado ahora por la soberanía de los ciudadanos con derechos políticos.

Las constituciones democráticas ensayan en la actualidad nuevos mecanismos de concertación entre las fuerzas sociales con representación, tendentes a lograr una mayor unanimidad en la toma de decisiones colectivas, lo que significa la ampliación de la libertad jurídica a más personas. La igualdad democrática es en consecuencia formal, vacía de contenido, pues se refiere al derecho a la libertad de quienes tienen derechos políticos. Por ello resulta falaz afirmar que la democracia implica la búsqueda de la igualdad material de los ciudadanos. Si bien esta puede ser un objetivo de las políticas públicas, no es un rasgo esencial de la democracia en su acepción jurídica.

Las sociedades democráticas, sostiene Kelsen, rechazan cualquier tutelaje ajeno a su voluntad. Ahí los sujetos se reconocen como iguales ante la ley, lo que genera lazos de solidaridad entre ellos (Kelsen, 1974). Otra virtud de la participación democrática que nuestros autores reconocen es la promoción de la educación política de los ciudadanos. Mill enfatiza los efectos positivos que produce en los hombres el desempeño de funciones públicas, ya que el contacto con intereses de otros grupos sociales y la conciliación de opiniones encontradas hacen que los individuos superen el estrecho círculo de sus preocupaciones personales y se interesen por el bienestar general (Mill, 1982). De lo anterior se puede concluir, citando a Kelsen, que la democracia, en tanto método para la creación del orden estatal,

es compatible aún con el mayor predominio del poder del estado sobre el individuo e incluso con el total aniquilamiento de la libertad individual y con la negación del ideal del liberalismo. Y la historia demuestra que el poder del Estado democrático no propende a la expansión menos que el autocrático. (Kelsen, 1974, p. 24)

En este punto la posición de Mill (1982) es opuesta a la de Kelsen. El filósofo inglés piensa que la libertad individual, entendida en un sentido natural como rechazo a cualquier autoridad o regulación, debe prevalecer en todos aquellos asuntos que afectan únicamente a la persona, es decir, que no tienen consecuencias negativas para otros o que su omisión no anula un bien a los demás. Es necesario que así sea, aún si las acciones libremente ejecutadas son dañinas para el sujeto. Esta idea está 
detrás de las posiciones que abogan por que el Estado no dicte a los individuos cómo comportarse, el plan de vida o las costumbres que deben seguir.

Un argumento adicional a favor de esta tesis es que la pluralidad de comportamientos, de formas de vida y de ideas impulsa el desarrollo social. El sistema que coarta esta clase de libertad, obligando a los ciudadanos a seguir una línea de conducta homogénea, los condena al atraso y a la minoría de edad. El régimen representativo está obligado a respetar este ámbito de libertades y no influir en las decisiones personales. Por tal motivo, toda intervención suya en los asuntos privados de los hombres es ilegítima y violatoria de sus derechos (Mill, 1982). El liberalismo, que surge con estas ideas a mediados del siglo xviII, postula en el campo económico la no intromisión del gobierno en el mercado y la libre competencia como mecanismo para determinar precios, salarios y asignación de recursos.

Desde la perspectiva kelseniana, el intervencionismo gubernamental no significa pérdida de libertad entendida en su sentido político, el único posible en la democracia; por ello la restricción de libertades civiles o económicas es compatible, conceptualmente, con un régimen representativo. Cuando se veda al gobierno la intervención en ciertas áreas de la vida social o privada de los hombres argumentando violación de la esfera de libertades individuales, se hace uso de la noción naturalista de libertad para justificar una ideología o determinada política económica, otorgándosele de esta forma un sustento incuestionable (Kelsen, 1974). Esto lleva a la idea, como reconoce el propio Stuart Mill (1982), de que las funciones del gobierno no son universales, sino que dependen de los acuerdos alcanzados por las fuerzas organizadas políticamente en cada lugar.

Ahora bien, es cierto que el desarrollo histórico del capitalismo en Europa y América estuvo estrechamente vinculado con el florecimiento de la democracia representativa. Sin embargo, observamos actualmente que hay sistemas, que sin duda calificaríamos de autocráticos, los cuales promueven políticas de corte liberal. La democracia puede convivir entonces con cualquier tipo de doctrina económica. Por ello, diremos con Kelsen, que es "una corrupción aplicar (dicho) vocablo que tanto ideológica como prácticamente significa un método para la creación del orden social, al contenido de este mismo orden, que es completamente independiente" (Kelsen, 1974, p. 25) 


\section{Conclusiones}

Decíamos al inicio que ser demócrata y no ser liberal, es decir, no estar a favor de que, para ponerlo en palabras de Rawls, las personas gocen del mayor catálogo de libertades posible que sea compatible con el hecho de que los demás miembros de la sociedad también disfruten de ellas, no implica una contradicción conceptual o lógica, sino en todo caso una de carácter performativo. Estas contradicciones se dan cuando el contenido de una afirmación contradice los supuestos necesarios para enunciarla. Por ejemplo, si digo "está lloviendo pero no lo creo", en la misma oración niego una condición para poder decir con sentido que un cierto estado de cosas " $\mathrm{x}$ " está teniendo lugar, a saber, que lo crea.

Este es también el caso cuando afirmo que estoy a favor de la democracia pero en contra de la tolerancia, de la libre discusión de las ideas o de que las personas elijan su plan de vida sin interferencias del Estado, pues la democracia es más vigorosa ahí donde todos los puntos de vista se debaten abiertamente y ninguno se impone por la fuerza ${ }^{1}$. Kelsen afirma que la democracia está asociada a una visión moral del mundo de corte relativista, para la cual no hay verdades absolutas acerca de lo justo, lo bueno o la mejor forma de organización social. Como cada opinión vale en principio lo mismo que las otras, es natural que se simpatice con un método democrático de toma de decisiones.

Por el contrario, quien sostiene la existencia de verdades absolutas y, por lo tanto, de personas con acceso privilegiado a ellas, tenderá a favorecer los sistemas autoritarios. Sin embargo, como Kelsen (1974) mismo admite, las contradicciones en este campo son posibles, ya que a final de cuentas se trata de asuntos en los cuales no domina la razón, sino la voluntad. Por ello, se puede ser demócrata y pensar que no todos tenemos los mismos derechos con base en una visión elitista de la sociedad, o estar en contra del libre y público examen de las ideas, de los gobiernos transparentes o de la investigación científica sin fines políticos.

Así mismo, es factible pensar, sin contradicción, un Estado absolutista que limitara el poder del monarca, al estilo liberal-democrático, aunque no haya razones históricas para esperarlo. Si bien Kelsen asocia al autócrata un carácter solipsista, una marcada

1 Anna Pintore señala también que es una inconsistencia pragmática ser partidario de la democracia pero no del relativismo (Pintore, 2000, pp. 121-122). 
voluntad de poder y una concepción ético-filosófica absolutista, es lógicamente posible que este conviniera en autolimitarse. Esta sería una inconsistencia performativa, pero como él mismo lo advierte:

But just because it is within the soul of the empirical human being and not within a sphere of pure reason that politics and philosophy originate, we must not expect that a definite political view will always and everywhere be combined with the philosophical system which logically corresponds to it. (Kelsen, 1955, p. 15)

Tenemos entonces que la relación entre democracia y liberalismo no es conceptual ni meramente contingente, sino pragmática. No se trata de un vínculo necesario, pero tampoco casual, sino de que este sistema requiere de dicha ideología para florecer y viceversa. La democracia necesita individuos libres y participativos y, por otra parte, esta forma de gobierno tiende a limitar el poder de los gobernantes, con lo que se propician las libertades y los derechos de los individuos. Habría que apuntar, finalmente, que aunque son posibles las contradicciones performativas y, por lo tanto, ser demócrata y antiliberal, el liberalismo es la visión del mundo social coherente con el sistema democrático, y esta concepción es la que mejor prepara a los ciudadanos para el ejercicio de la democracia.

\section{Referencias}

Bobbio, N. (1989a). Estado, gobierno y sociedad. México: Fondo de Cultura Económica.

Bobbio, N. (1989b). Liberalismo y democracia. México: Fondo de Cultura Económica.

Bobbio, N. (2012). El futuro de la democracia. México: Fondo de Cultura Económica.

Fuller, L. (1978). The Morality of Law. New Haven: Yale University Press.

Kelsen, H. (1942). General Theory of Law and State. Cambridge, Massachusetts: Harvard University Press.

Kelsen, H. (1955). Foundations of Democracy. Ethics, 66(1, 2), 1-101.

Kelsen, H. (1965). Teoría general del estado. México: Editora Nacional. 
Kelsen, H. (1969). Sobre los límites entre el método sociológico y jurídico. Revista de la facultad de derecho de México, 75, 45-73.

Kelsen, H. (1971). What is Justice? Justice, Law and Politics in the Mirror of Science. Collected Essays. Los Ángeles: University of California Press.

Kelsen, H. (1974). Esencia y valor de la democracia. México: Editora Nacional.

Kelsen, H. (1979). La idea del derecho natural y otros ensayos. México: Editora Nacional.

Kelsen, H. (2002). La teoría pura del derecho. México: Porrúa.

Mill, J.S. (1970). Principios de economía política. México: Fondo de Cultura Económica.

Mill, J.S. (1977). Sobre la libertad. Madrid: Aguilar.

Mill, J.S. (1982). El gobierno representativo. Madrid: Tecnos.

Mill, J.S. (2005). Autobiografía. Madrid: Alianza Editorial.

Mill, J.S. (2010). El utilitarismo. Madrid: Alianza Editorial.

Pintore, A. (2000). Democracia sin derechos. En torno al Kelsen democrático. Doxa, 23, 119-144. 